\title{
The effects of the interaction of myosin essential light chain isoforms with actin in skeletal muscles
}

\author{
Hanna Nieznańska, Krzysztof Nieznański and Dariusz Stępkowski \\ Department of Muscle Biochemistry, Nencki Institute of Experimental Biology, Polish Academy of \\ Sciences, Warszawa, Poland
}

Received: 21 May, 2002; revised: 02 July, 2002; accepted: 26 August, 2002

Key words: skeletal muscle biochemistry, myofibrillar ATPase, thin filament regulatory proteins

\begin{abstract}
In order to compare the ability of different isoforms of myosin essential light chain to interact with actin, the effect of the latter protein on the proteolytic susceptibility of myosin light chains (MLC-1S and MLC-1V - slow specific and same as ventricular isoform) from slow skeletal muscle was examined. Actin protects both slow muscle essential light chain isoforms from papain digestion, similarly as observed for fast skeletal muscle myosin (Nieznańska et al., 1998, Biochim. Biophys. Acta 1383: 71). The effect of actin decreases as ionic strength rises above physiological values for both fast and slow skeletal myosin, confirming the ionic character of the actin-essential light chain interaction. To better understand the role of this interaction, we examined the effect of synthetic peptides spanning the 10-amino-acid N-terminal sequences of myosin light chain 1 from fast skeletal muscle (MLC-1F) (MLCFpep: KKDVKKPAAA), MLC-1S (MLCSpep: KKDVPVKKPA) and MLC-1V (MLCVpep: KPEPKKDDAK) on the myofibrillar ATPase of fast and slow skeletal muscle. In the presence of MLCFpep, we observed an about 19\% increase, and in the presence of MLCSpep about 36\% increase, in the myofibrillar ATPase activity of fast muscle. On the other hand, in myofibrillar preparations from slow skeletal muscle, MLCSpep as well as MLCVpep caused a lowering of the ATPase activity by about $36 \%$. The above results suggest that MLCSpep induces opposite effects on ATPase activity, depending on the
\end{abstract}

\footnotetext{
Holder of a scholarship from the Foundation for Polish Science.

${ }^{凶}$ Address correspondence to Dr. Dariusz Stępkowski, Department of Muscle Biochemistry, Nencki Institute of Experimental Biology, L. Pasteura 3, 02-093 Warszawa, Poland; fax: (48 22) 822 5342; e-mail: dareks@nencki.gov.pl

Abbreviations: DTT, dithiothreitol; MHC, myosin heavy chain; MLC, myosin light chain; MLC-1F (A1, LC1), long isoform of fast skeletal muscle myosin essential light chain; MLC-3F (A2, LC3), short isoform of fast skeletal muscle myosin essential light chain; MLC-1V, slow skeletal muscle/ventricular myosin essential light chain; MLC-1S, slow skeletal muscle myosin essential light chain; $\mathrm{pCa}$, negative decimal logarithm of free $\mathrm{Ca}^{2+}$ concentration; $\mathrm{pCa}_{50 \%}$, value of $\mathrm{pCa}$ corresponding to $50 \%$ maximal ATPase activity; $\mathrm{P}_{\mathrm{i}}$, orthophosphate; PMSF, phenylmethylsulfonyl fluoride; $\mathrm{S} 1$, myosin subfragment 1.
} 
type of myofibrils, but not through its specific $\mathrm{N}$-terminal sequence - which differs from other MLC N-terminal peptides. Our observations lead to the conclusion that the action of different isoforms of long essential light chain is similar in slow and fast skeletal muscle. However the interaction of essential light chains with actin leads to different physiological effects probably depending on the isoforms of other myofibrillar proteins.

All class II myosins are hexamers composed of two heavy chains (MHC) and four light chains (MLC), from which two are regulatory and two essential (also called alkali) light chains. There are two major types of essential light chain: short and long. The latter isoform possesses an additional sequence at the N-terminus (Frank \&Weeds, 1974; Kurabayashi et al., 1988; Hailstones \& Gunning, 1990). This sequence contains characteristic repeats of Pro and Ala residues and positively charged amino acids at the very N-terminus (Table 1). The long type of essential light chain is more commonly present in striated muscles than the short type and its presence coincides with the occurrence of the troponin-tropomyosin regulatory system. In fast twitch skeletal muscles (fast muscles), the short isoform is represented by MLC-3F (called also A2 or LC3) and the long isoform by MLC-1F (called also A1 or LC1) (Periasamy et al., 1984; Swynghedauw, 1986). Slow twitch skeletal muscle (slow muscle) cells express only long isoforms of essential light chain: one of which is identical with MLC-1V - expressed in the ventricles of cardiac muscle - and the second - MLC-1S - is specific for slow muscle cells (Barton et al., 1985; Swynghedauw, 1986; Schaub et al., 1998). Another isoform of long essential chain, called MLC-1A, is present in the atria of cardiac muscle (Price et al., 1980; Kurabayashi et al., 1988; Swynghedauw, 1986; Morano et al., 1991).

There is strong evidence for an interaction of the long isoforms of essential light chain with actin. S1(A1) and S1(A2) NMR spectra measurements, made by Prince et al. (1981), indicated that the high mobility of the N-terminal segment of A1 decreased markedly after the formation of S1(A1)-actin complex. Cross-linking of myosin from fast muscle with actin leads to, amongst others, the formation of a MLC-1F-actin complex (Andreev \& Borejdo, 1995). Moreover, cross-linking of a peptide spanning the 13-amino-acid N-terminal sequence of MLC-1F with actin demonstrates that this basic sequence plays an important role in the interaction of myosin essential light chain with actin (Hayashibara \& Miyanishi, 1994). It was shown that essential MLC binds to the acidic C-terminus of actin (Sutoh, 1982). We showed, applying limited proteolysis of MLC-1F by papain, that the $\mathrm{N}$-terminal part of this light chain also interacts with actin at physiological ionic strengths (Nieznańska et al., 1998).

It is supposed that the long isoform of essential light chain, interacting with actin through the positively charged N-terminus, can modulate the contraction of skeletal as well as cardiac muscle. The isoform of fast skeletal muscle myosin containing only MLC-3F moved actin filaments, in motility assays, with a higher velocity than that containing MLC-1F (Lowey et al., 1993). Isolated skeletal muscle fibers with a relatively higher MLC-3F/ MLC-1F ratio shortened faster (Sweeney et al., 1988; Greaser et al., 1988). Rarick et al. (1996) described a supramaximal stimulation of cardiac myofibrillar ATPase by a synthetic peptide spanning the N-terminal sequence of MLC-1V. This effect of the peptide was only observed in the presence of thin filament regulatory proteins.

In this paper we provide, for the first time, evidence for an interaction of essential light chains from slow skeletal muscle with actin. We describe the effects of three different synthetic peptides corresponding to 10-aminoacid N-terminal sequences of MLC-1F, MLC-1S and MLC-1V on the activity of fast and slow skeletal muscle myofibrillar ATPase. 
On the basis of the obtained results we propose a hypothetical mechanism of the action of the synthetic peptides in myofibrils. We also conclude that the function of different isoforms of long essential MLC is similar in both slow and fast skeletal muscle but that the physiological effects of essential MLC interaction with actin are based on the diversity of isoforms of other myofibrillar proteins.

\section{MATERIALS AND METHODS}

Protein preparation. Dephosphorylated fast skeletal myosin was purified from rabbit back muscles, as described previously (Stępkowski et al., 1985). Slow skeletal myosin was isolated from myofibrils by the method described by Tartakowski (1978) from rabbit semimembranosus proprius muscle with the modifications described by Podlubnaya et al. (2000). F-actin was prepared according to the method of Strzelecka-Gołaszewska et al. (1975). Troponin and tropomyosin were obtained from rabbit skeletal muscles according to Ebashi et al. (1968) and Smillie (1982), respectively. Fast and slow skeletal muscle myofibrillar preparations were obtained by the modified method of Herrmann et al. (1993). About $9 \mathrm{~g}$ of chopped muscles were homogenized in 10 volumes of buffer A $(5 \mathrm{mM}$ EDTA, 0.5\% (w/v) Triton X-100, 0.1 M sodium acetate, $5 \mathrm{mM} \mathrm{KCl,} 2 \mathrm{mM}$ DTT, $50 \mathrm{mM}$ Tris, pH 7.4, 0.5 mM NaN $3,0.2 \mathrm{mM}$ PMSF and 1 tablet of Complete-protease inhibitor cocktail (Boehringer Mannheim, Germany) /100 ml of buffer) using a Polytron homogenizer and pelleted (6000 r.p.m. for $10 \mathrm{~min}$ in a SS-34 Sorval rotor). The obtained pellet was homogenized in 10 volumes of buffer B containing: $0.1 \mathrm{M}$ sodium acetate, $5 \mathrm{mM} \mathrm{KCl}, 2 \mathrm{mM}$ DTT, $50 \mathrm{mM}$ Tris, $\mathrm{pH}$ 7.4, $2 \mathrm{mM}$ magnesium acetate, $0.5 \mathrm{mM} \mathrm{NaN}_{3}$ and $0.2 \mathrm{mM}$ PMSF. After centrifugation, pelleted myofibrils were washed 4 times in buffer B (without homogenization). The myofibrillar preparations were stored on ice for up to 2 days. The molar ratio of MLC-1F (A1) to MLC-3F (A2) in the myofibrillar preparations obtained from rabbit back muscle (fast twitch muscle) was approx. $1.99 \pm 0.43, \mathrm{n}=20$. The molar ratio of MLC-1S to MLC-1V in the myofibrillar preparations from semimembranosus proprius (slow twitch muscle) was approx. $3 \pm 0.7, \mathrm{n}=8$. An example of an electrophoregram of myofibrillar preparations is presented in Fig. 1.

Concentrations of myofibrils were determined by the biuret method (Gornall et al., 1949) and concentrations of myosin and actin from their absorbance at $280 \mathrm{~nm}$, using absorption coefficients of $\mathrm{A}_{1 \mathrm{~cm}, 280}^{1 \%} 5.6$ and 11, respectively.

Peptides spanning the N-terminal sequence of MLC-1F (MLCFpep: KKDVKKPAAA), MLC-1S (MLCSpep: KKDVPVKKPA) and MLC-1V (MLCV: KPEPKKDDAK) were synthesized as described previously (Nieznańska et al., 1998), dissolved in small volumes of 20 $\mathrm{mM}$ Tris, $\mathrm{pH}$ 7.0, and stored frozen.

Digestion of myosin essential light chains with papain. Fast or slow skeletal myosin was digested with papain at a 250:1 $(\mathrm{w} / \mathrm{w})$ ratio, for $10 \mathrm{~min}$ at $25^{\circ} \mathrm{C}$. The reaction was performed in a buffer containing: 100 $\mathrm{mM} \mathrm{NaCl}$ (if not stated otherwise), $20 \mathrm{mM}$ Tris, $\mathrm{pH} 7.0,1 \mathrm{mM} \mathrm{MgCl} 2$ and $0.1 \mathrm{mM} \mathrm{CaCl}_{2}$. Proteolysis was stopped by the addition of 1 $\mathrm{mM}$ iodoacetic acid and boiling of samples with electrophoresis sample buffer. Then, the samples were submitted to SDS/PAGE and the extent of essential chain digestion determined by densitometric analysis of the gels.

MgATPase measurements. Myofibrillar MgATPase activity was measured as a function of $\mathrm{Ca}^{2+}$ concentration by the method of Fiske \& SubbaRow (1925). The MgATPase reaction of myofibrils $(0.2 \mathrm{mg} / \mathrm{ml})$ was carried out at $26^{\circ} \mathrm{C}$ in a buffer containing $50 \mathrm{mM} \mathrm{KCl}$, $40 \mathrm{mM}$ imidazole, $\mathrm{pH} 7.0,3 \mathrm{mM} \mathrm{MgCl}_{2}, 2 \mathrm{mM}$ calcium buffer and $1 \mathrm{mM}$ ATP in the absence or presence of $50 \mathrm{nM}$ synthetic N-terminal peptide. Stock solutions of calcium buffers were prepared by mixing $50 \mathrm{mM}$ equimolar $\mathrm{Ca}^{2+}$-EGTA, pH 7.0, solution and $50 \mathrm{mM}$ 
EGTA, pH 7.0, solution in different proportions. Free calcium concentrations were calculated using the binding constants given by Fabiato \& Fabiato (1979). The reaction was quenched by the addition of an equal volume of $3 \%(\mathrm{w} / \mathrm{v})$ SDS after 5 min for fast skeletal myofibrils and after $10 \mathrm{~min}$ for slow skeletal myofibrils.

Electrophoresis and densitometry. SDS/ PAGE was performed on slab 5\% stacking/ $15 \%$ separating gels according to Laemmli (1970). After staining with Coomassie Brilliant Blue R250 and destaining, the gels were scanned on a Molecular Dynamics Personal Densitometer and quantitatively analysed using the Image Quant software.

\section{RESULTS}

The results of our previous study (Nieznańska et al., 1998) showed that the N-terminal part of MLC-1F from fast skeletal muscle is protected from papain cleavage in the presence of actin at a significant molar excess over myosin heads. It is believed that this ef-

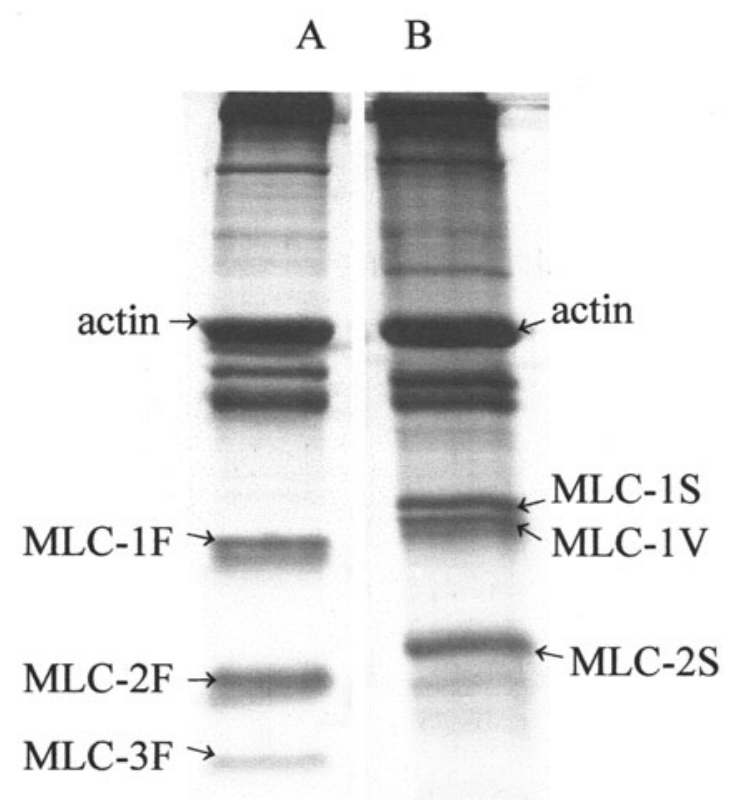

Figure 1. Electrophoregram of myofibrillar preparations from rabbit back muscle (A) and semimembranosus proprius (B). fect is a result of the direct binding of the $\mathrm{N}$-terminus of essential light chain to actin. In the present study we tested whether the proteolytic protection is conferred by actin also in the case of slow skeletal myosin. In our experiments we used myosin from rabbit semimembranosus proprius muscle which expresses $100 \%$ type I MHC and 100\% slow-type MLC isoforms (MLC-1S, MLC-1V, MLC-2S) (Bacou et al., 1996). Figure 2 shows the result of digestion of slow myosin by papain at increasing $\mathrm{F}$-actin/myosin ratios. As in the case of MLC-1F (Nieznańska et al., 1998), actin protected the N-terminal domains of MLC-1S and MLC-1V from papain digestion at near physiological ionic strength. An increase of $\mathrm{NaCl}$ concentration to $320 \mathrm{mM}$ caused an about 14-fold reduction in the protection of MLC-1F by actin (Fig. 3) as well as 2-fold and 6-fold reduction in the protection of MLC-1S and MLC-1V, respectively (Fig. 4). Figures 3 and 4 show the difference between the amount of undigested essential light chains in the presence and absence of actin, thus the presented effects are not a result of the influence of salt on the activity of papain. The obtained results confirm the ionic character of the essential light chain-actin interaction. The differences in the degree of protection by actin can be explained by the specific composition of the N-terminal sequences of essential MLCs.

In order to determine a role for the interaction of different essential light chains with actin in the contraction of skeletal muscles, we examined the effects of synthetic 10-amino-acid peptides spanning the N-terminal sequences of MLC-1F (MLCFpep: KKDVKKPAAA), MLC-1S (MLCSpep: KKDVPVKKPA) and MLC-1V (MLCVpep: KPEPKKDDAK) on the activity of myofibrillar ATPase from fast and slow muscle. Figure 5 shows that both MLCFpep (corresponding to the N-terminus of endogenous light chain) and MLCSpep (corresponding to the $\mathrm{N}$-terminus of exogenous light chain) induced an increase in the activity of myofibrillar ATPase from fast skeletal muscle. In the presence of MLCFpep we observed 


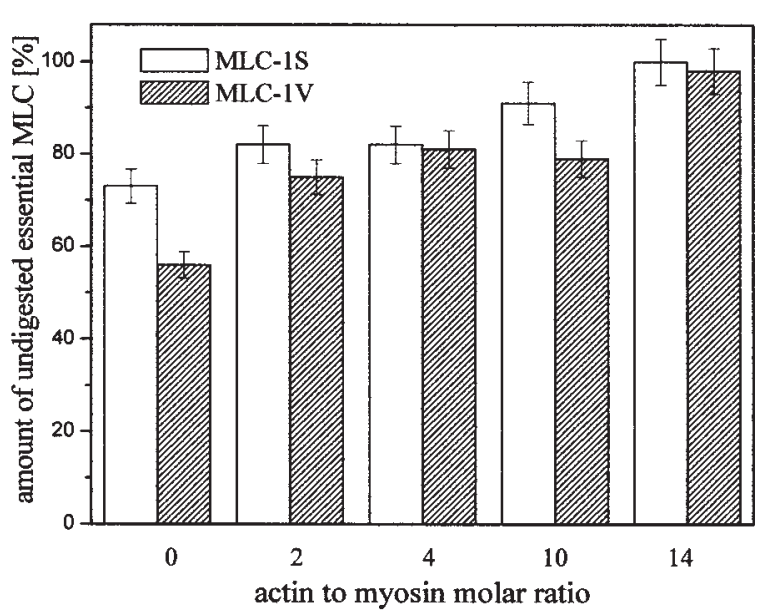

Figure 2. Influence of actin on the digestion of slow skeletal myosin light chains (MLC-1S and MLC-1V) by papain.

Slow skeletal myosin at $2.02 \mu \mathrm{M}$ was digested in the presence of increasing $\mathrm{F}$-actin concentrations under the conditions described in Section 2. One hundred percent was adopted as the amount of myosin essential light chains in undigested myosin preparation. The presented data are mean \pm S.E., $n=3$.

an increase of about $19 \%$, whereas in the presence of MLCSpep an about 36\% increase in the ATPase activity. Marked effects appeared in the $\mathrm{pCa}$ range 5.72-4.59. There was no significant shift in the $\mathrm{pCa}_{50 \%}$ value. However, Hill analysis of the obtained curves showed an about 1.8-fold increase of the cooperativity coefficient of ATPase $\mathrm{Ca}^{2+}$-activation after the addition of MLCSpep and about 2.1-fold increase in the presence of MLCFpep. Surprisingly, an opposite effect of the peptides on the activity of myofibrillar ATPase from slow muscle was observed (Fig. 6). MLCSpep as well as MLCVpep (corresponding to the N-termini of endogenous light chains) decreased the activity of the ATPase by about $36 \%$. No significant shift in $\mathrm{pCa}_{50} \%$ value was observed. The Hill coefficient was only slightly increased by the peptides (from 1.7 for control to 1.9 and 2.0 in the presence of MLCSpep and MLCVpep, respectively). The fact that the same peptide, MLCSpep, caused opposite effects in two types of myofibrils suggested that the specific sequence of the $\mathrm{N}$-terminal part of essential light chain

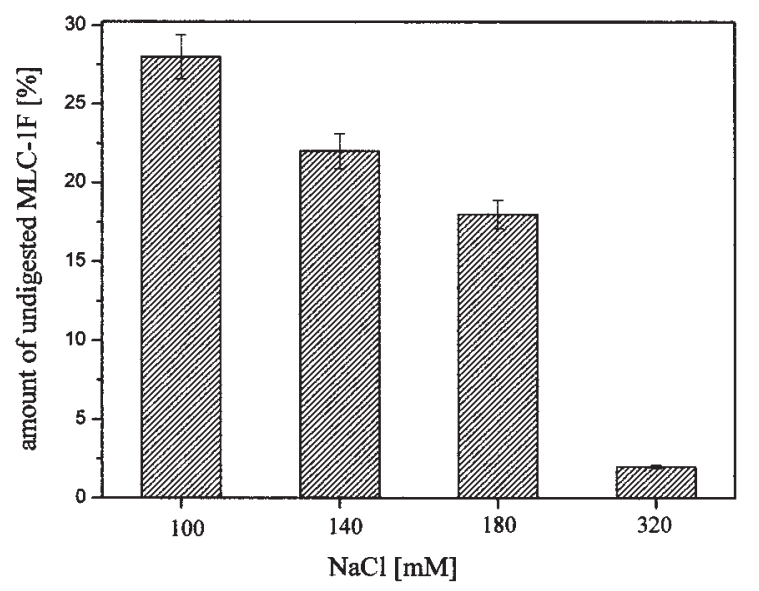

Figure 3. Protection of fast skeletal myosin essential light chain (MLC-1F) by actin with increasing ionic strength.

Fast skeletal myosin at $3 \mu \mathrm{M}$ was digested in the absence and presence of $42 \mu \mathrm{M}$ actin at increasing $\mathrm{NaCl}$ concentrations. The presented result is the difference between the amount of undigested MLC- $1 \mathrm{~F}$ in the presence and absence of actin. The amount of essential light chain in untreated myosin preparation is taken as $100 \%$. The presented data are mean \pm S.E., $n=4$.

isoform is not responsible for the direction of its effect on the ATPase activity. In an attempt to determine which myofibrillar proteins are required for the above described effect, we checked the influence of MLCFpep and MLCSpep on the activity of an in vitro reconstituted ATPase from purified myosin, actin, tropomyosin and troponin. These proteins were isolated from fast skeletal muscle and mixed at a molar ratio of myosin: actin : tropomyosin : troponin of $1: 16: 4.6: 11.4$. Both peptides induced an increase in the activity of the reconstituted ATPase, similar to that observed for the fast muscle myofibrillar ATPase. MLCFpep caused a $22.3 \%$ increase in the ATPase activity at pCa 4.6, and MLCSpep an increase by about $29 \%$.

\section{DISCUSSION}

From our proteolytic experiments it is apparent that actin interacts not only with the N-terminus of MLC-1F but also with the 


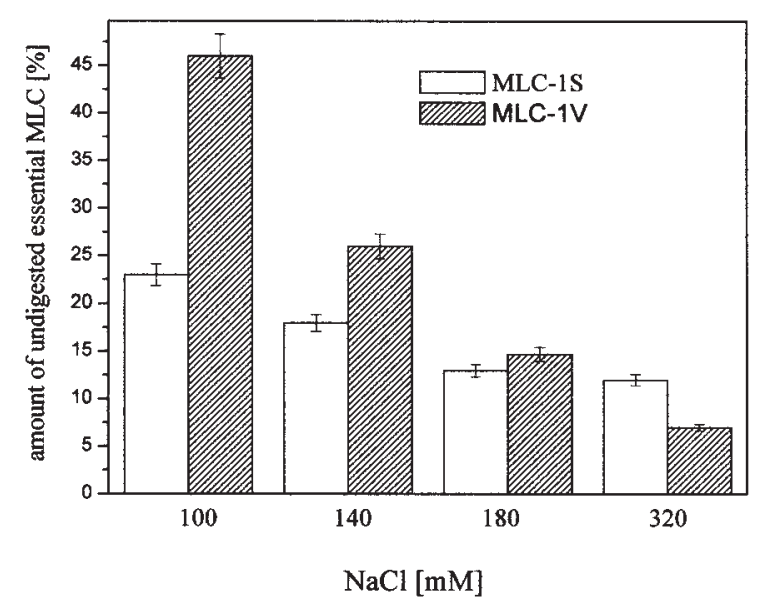

Figure 4. Protection of slow skeletal myosin essential light chains (MLC-1S and MLC-1V) by actin with increasing ionic strength.

The conditions of the experiment are the same as for that presented in Fig. 2. The presented data are mean \pm S.E., $n=3$.

N-terminal sequences of slow myosin essential light chain isoforms MLC-1S and MLC-1V (Fig. 2). This observation supports the proposal that the actin binding ability is a common feature of all long isoforms of myosin essential light chain. Although this interaction has an ionic character, it can also occur under

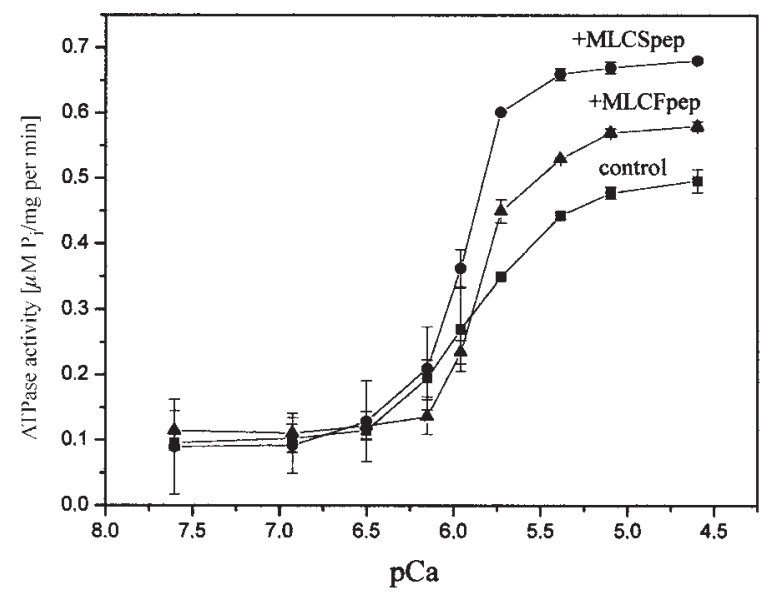

Figure 5. Effect of MLCFpep and MLCSpep on the activity of myofibrillar ATPase from fast skeletal muscle.

$\mathrm{Ca}^{2+}$-dependent MgATPase activity measurements of myofibrils prepared from rabbit back muscle were carried out under conditions described in Section 2. The presented data are mean \pm S.E., $n=3-4$.

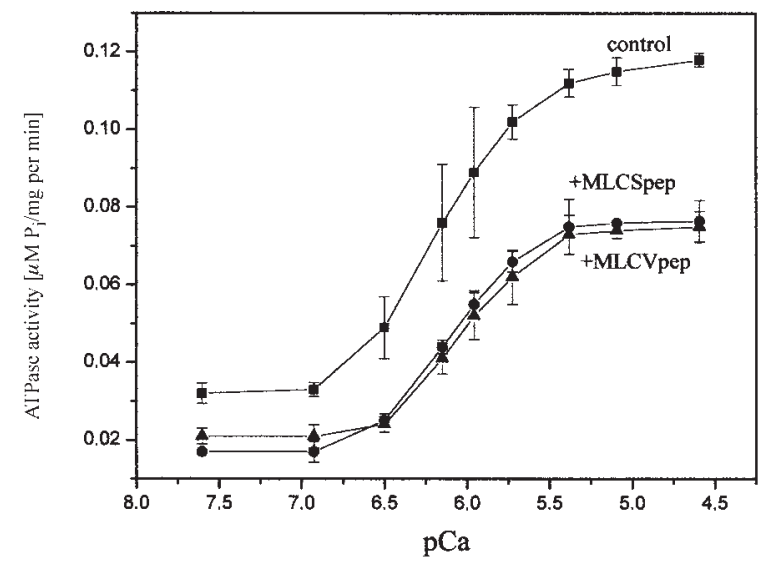

Figure 6. Effect of MLCSpep and MLCVpep on the activity of myofibrillar ATPase from slow skeletal muscle.

$\mathrm{Ca}^{2+}$-dependent MgATPase activity measurements of myofibrils prepared from rabbit semimembranosus proprius muscle were carried out under the conditions described in Section 2. The presented data are mean \pm \pm S.E., $\mathrm{n}=3-4$.

physiological ionic strength (Figs. 3 and 4). The differences observed in the extent of MLC isoforms protection by actin (Figs. 3 and 4) are correlated with the net charge of the 20 $\mathrm{N}$-terminal residues of the essential light chains (Table 1). The actin protection of MLC-1F and MLC-1V, whose N-terminal sequences (not taking into consideration the very $\mathrm{N}$-terminal trimethylated residue) have a +3 net charge, is more influenced by a raise in salt concentration than the protection of MLC-1S, whose N-terminus has a +4 net charge and thus can probably bind to the acidic C-terminus of actin more strongly than MLC-1F or MLC-1V. The above mentioned differences are in agreement with the effects of exchanging essential MLC isoforms on the maximal velocity of shortening of fast skeletal muscle fibers, described by Sweeney (1995). Incorporation of MLC-1S into myosin decreased the shortening velocity to a greater extent than the exchange with MLC-1V which in turn gave a greater effect than the exchange with MLC-1F. It should be expected that not only the net charge of the N-terminal region of the light chain molecule, but also the 
Table 1 Alignment of N-terminal amino-acid sequences of different long-type myosin essential light chains.

Conserved lysine residues are depicted in bold „+” and „-" indicate the charge of the residue. The presented sequences were obtained from the SWISS-PROT database and alignment was performed using ANTHEPROT software (Deleage et al., 1989).

\begin{tabular}{|c|c|c|}
\hline Isoform & Source & Sequence \\
\hline MLC-1V & $\begin{array}{l}\text { human, cardiac ventricles and } \\
\text { slow skeletal muscle }\end{array}$ & 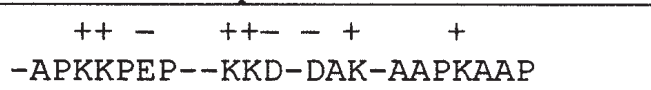 \\
\hline MLC-1V & $\begin{array}{l}\text { mouse, cardiac ventricles and } \\
\text { slow skeletal muscle }\end{array}$ & $\begin{array}{c}++-\quad++-\quad+\quad+ \\
\text {-APKKPEP--KKD-DAKAAAPKAA }\end{array}$ \\
\hline MLC-1V & $\begin{array}{l}\text { rat, cardiac ventricles and slow } \\
\text { skeletal muscle }\end{array}$ & $\begin{array}{ccc}++- & ++- & -+ \\
\text {-APKKPEP--KKD-DAKTAAPKAA }\end{array}$ \\
\hline MLC-1A & $\begin{array}{l}\text { human, cardiac atria and } \\
\text { embrional muscles }\end{array}$ & 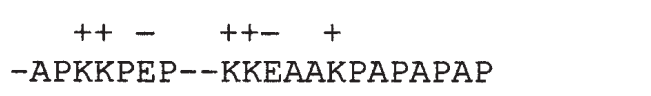 \\
\hline MLC-1A & $\begin{array}{l}\text { mouse, cardiac atria and } \\
\text { embrional muscles }\end{array}$ & $\begin{array}{c}++-\quad++-\quad+ \\
- \text { PPKKPEP- } \\
+ \text { KKEAAKPAAAPAP }\end{array}$ \\
\hline MLC-1A & $\begin{array}{l}\text { rat, cardiac atria and embrional } \\
\text { muscles }\end{array}$ & $\begin{array}{c}++-\quad+++\quad+ \\
\text { - PPKKРEP--KKETAKVAAAPAP }\end{array}$ \\
\hline MLC-1F & chicken, fast skeletal muscle & $\begin{array}{c}++-\quad++ \\
-- \text { PKK-DV--KKP--AAAAAPAPAPAP }\end{array}$ \\
\hline MLC-1F & human, fast skeletal muscle & $\begin{array}{l}++-\quad++ \\
\text {-APKK-DV--KKPVAAAAAAPAPA }\end{array}$ \\
\hline MLC-1F & rabbit, fast skeletal muscle & $\begin{array}{l}++-\quad++ \\
\text {-APKK-DV- } \\
+ \text { KKP--AAAAAPAPAPA }\end{array}$ \\
\hline MLC-1F & mouse, fast skeletal muscle & $\begin{array}{c}++-\quad++ \\
- \text { APKK-DV--KKP-----AAA-PAPAPAPA }\end{array}$ \\
\hline MLC-1F & rat, fast skeletal muscle & $\begin{array}{c}++-\quad++ \\
- \text { APKK-DV--KKP----AAAAPAPAPAP }\end{array}$ \\
\hline MLC-1S & human, slow skeletal muscle & $\begin{array}{cccc}++ & + & ++ & + \\
\text { MPPKK-DVPVKKPAGPSISKP }\end{array}$ \\
\hline
\end{tabular}

specific location of the charged residues influences the strength of the interaction with actin. From recent experiments (Timson et al., 1999), it is apparent that in binding to the C-terminus of actin molecule are involved only the very $\mathrm{N}$-terminal residues of the essential light chain. According to the above study, the most important role in this process seems to be played by Lys residues in positions 3 and 4 (rabbit MLC-1F sequence). These residues are conserved among all known sequences of long isoforms of essential MLC as well as another pair of Lys in positions 7 and 8 (Table 1). The above fact may also suggest that the other pair of Lys play an important role in essential MLC-actin interaction. The function of this interaction, despite many efforts, remains only partly understood. The observations that fast skeletal muscle fibers with a relatively higher content of short essential MLC, which does not bind to actin, shortened faster than fibers with a higher content of MLC-1F (Sweeney et al., 1988; Greaser et al., 1988), and that myosin containing MLC-3F moved actin filaments in motility assays with a higher velocity than myosin with MLC-1F (Lowey et al., 1993), lead to the supposition that long essential light chain binding to actin lowers the rate of cross-bridge cycling (Sweeney, 1995; Morano, 1999). Another aspect of this interaction is the introduction of a positive charge (of the essential light chain $\mathrm{N}$-terminus) into the thin filament. Experiments with synthetic peptides spanning the N-terminal sequences of long essential light chains were performed. It has been shown that a synthetic peptide corresponding to the sequence 4 through 13 (KPEPKKDDAK) of the ventricular essential 
light chain (MLC-1V) increased contractility of chemically skinned and intact heart fibers (Morano et al., 1995). Rarick et al. (1996) showed that this synthetic peptide induces a supramaximal increase in the ATPase activity of cardiac-ventricular myofibrils at $\mathrm{pCa}$ values from 6.5 to 5.87, with no effect at low and maximal $\mathrm{Ca}^{2+}$ concentrations. In the present paper we extended these studies to fast and slow skeletal muscle myofibrils. The effects of MLCFpep and MLCSpep on the ATPase of fast muscle myofibrils, observed by us, resemble those obtained by Rarick et al. (1996) in respect to the direction of the effect (Fig. 5). However, a significant influence on the ATPase activity was observed in our experiments at submaximal and maximal $\mathrm{Ca}^{2+}$ concentrations (pCa: 5.72-4.59). The differences in the level of ATPase activation by MLCFpep and MLCSpep may be a result of the different affinities of these peptides for actin. On the other hand, MLCSpep and MLCVpep caused a decrease in the activity of slow muscle myofibrillar ATPase in the whole spectrum of calcium ion concentrations (Fig. 6). The most intriguing feature of MLCSpep is that it can increase or decrease ATPase activity depending on the type of the myofibrils examined (Figs. 5 and 6). In light of this observation the opposite effects of peptides in fast and slow myofibrillar preparations could not be simply explained by differences in the specific peptide sequence. The fact that a peptide of the same sequence (MLCVpep) induces opposite effects in myofibrils prepared from cardiac ventricles (Rarick et al., 1996) and from slow skeletal muscle (Fig. 6) also provides evidence confirming the idea that the specific sequence of the peptide is not responsible for the direction of the above described effects. However, the characteristic sequence of the peptides is necessary for their binding to actin, because as Morano \& Haase (1997) have shown, scrambled sequences of the 10-amino-acid peptides spanning the N-terminus of ventricular (MLCVpep) and atrial myosin essential light chain were not able to bind to actin.
Therefore, we consider the role of isoforms of other myofibrillar proteins that differentiate these preparations. The fact that MLCFpep and MLCSpep induced similar effects on the fast muscle myofibrillar ATPase and acto-myosin ATPase reconstructed only from myosin, actin, tropomyosin and troponin isolated from fast muscle, strictly limits the set of "suspected" proteins. The most probable candidates are isoforms of myosin heavy chain and regulatory proteins of the thin filament because both types of skeletal muscle express the same isoform of actin (Lompre et al., 1984; Swynghedauw, 1986; Lees-Miller \& Helfmann, 1991; de Nardi et al., 1993; Janmot \& d'Albis, 1994). Rarick et al. (1996) suggested that the synthetic peptide was not acting on myosin itself. It had no effect on the $\mathrm{K}^{+}$-EDTA-, $\mathrm{Ca}^{2+}$ - and $\mathrm{Mg}^{2+}$-ATPase activities of myosin purified from cardiac muscle. The effect of the peptide disappeared after extraction of thin filament regulatory proteins from cardiac myofibrils. We also observed no effect of the synthetic peptides when the sensitivity of skeletal myofibrils to $\mathrm{Ca}^{2+}$ was low, which can be explained by degradation of regulatory proteins. We believe that the interaction of the peptide with actin can induce opposite effects on the activity of myofibrillar ATPase according to the isoform type of thin filament regulatory proteins present in the preparation. However, it cannot be ruled out, at present, that the effect of the peptide may be also influenced by isoforms of myosin heavy chain. We assume that the long isoform of essential light chain can induce two different effects in the muscle cell:

- the first is associated with a "mechanical" lowering of the crossbridge cycling rate, resulting from the attachment of the myosin head to actin by the N-terminal part of essential light chain,

- the second is associated with introduction of a positive charge by the N-terminus of essential light chain into the thin filament.

In the first case, the interaction of light chain with actin leads to a lowering of the ac- 
tivity of myofibrillar ATPase in fast as well as in slow skeletal muscle. We assume that the second process - introduction of a positive charge - induces some conformational changes in the regulated thin filament. The conformational changes suggested above lead to a decrease or increase of the myofibrillar ATPase activity, probably depending on the type of regulatory proteins isoforms present in the preparation. We assume that the influence of essential MLC on the ATPase activity, resulting from the "mechanical" lowering of the crossbridge cycling rate, is stronger than that resulting from the introduction of the the positive charge into the thin filament. Addition of the synthetic peptide (at the concentration applied by us) does not affect the interaction of essential MLC with actin but potentiates the effect of essential MLC on the level of thin filament. Evaluation of this hypothesis requires further experiments aimed at relating the influence of essential MLC on actinmyosin interaction with the presence of thin filament regulatory proteins.

The authors wish to thank Prof. Irena Kąol for helpful discussion and comments on the manuscript.

\section{R E F E R E N C E S}

Andreev OA, Borejdo J. (1995) Binding of heavy-chain and essential light-chain 1 of S1 to actin depends on the degree of saturation of F-actin filaments with S1. Biochemistry.; 34: 14829-33.

Bacou F, Rouanet P, Barjot C, Janmot C, Vigneron P, d'Albis A. (1996) Expression of myosin isoforms in denervated cross-reinnervated and electrically stimulated rabbit muscles. Eur J Biochem.; 236: 539-47.

Barton PJ, Cohen A, Robert B, Fiszman MY, Bonhomme F, Guenet JL, Leader DP, Buckingham ME. (1985) The myosin alkali light chains of mouse ventricular and slow skeletal muscle are indistinguishable and are encoded by the same gene. $J$ Biol Chem.; 260: $8578-84$.

Deleage G, Clerc FF, Roux B, Gautheron DC. (1989) ANTHEPROT: IBM PC and Apple Macintosh versions. Comput Appl Biosci.; 5: 159-60.

deNardi C, Ausoni S, Moretti P, Gorza L, Velleca M, Buckingham M, Schiaffino S. (1993) Type 2X-myosin heavy chain is coded by a muscle fiber type-specific and developmentally regulated gene. J Cell Biol.; 123: 823-35.

Ebashi S, Kodama A, Ebashi F. (1968) Troponin I preparation and physiological function. $J$ Biochem (Tokyo).; 64: 465-77.

Fabiato A, Fabiato F. (1979) Calculator programs for computing the composition of the solutions containing multiple metals and ligands used for experiments in skinned muscle cells. J Physiol (Paris).; 75: 463-505.

Fiske CH, SubbaRow Y. (1925) The colorimetric determination of phosphorus. J Biol Chem.; 66: $375-400$.

Frank G, Weeds AG. (1974) The amino-acid sequence of the alkali light chains of rabbit skeletal-muscle myosin. Eur J Biochem.; 44: 317-34.

Gornall AG, Bardawill CJ, David MM. (1949) Determination of serum proteins by means of the biuret reaction. J Biol Chem.; 177: $751-66$.

Greaser ML, Moss RL, Reiser PJ. (1988) Variations in contractile properties of rabbit single muscle fibres in relation to troponin $\mathrm{T}$ isoforms and myosin light chains. $J$ Physiol.; 406: 85-98.

Hailstones DL, Gunning PW. (1990) Characterization of human myosin light chains 1sa and $3 \mathrm{~nm}$ : implications for isoform evolution and function. Mol Cell Biol.; 10: 1095-104.

Hayashibara T, Miyanishi T. (1994) Binding of the amino-terminal region of myosin alkali 1 light chain to actin and its effect on actin-myosin interaction. Biochemistry.; 33: 12821-7.

Herrmann C, Sleep J, Chaussepied P, Travers F, Barman T. (1993) A structural and kinetic 
study on myofibrils prevented from shortening by chemical cross-linking. Biochemistry.; 32: 7255-63.

Janmot C, d'Albis A. (1994) Electrophoretic separation of developmental and adult rabbit skeletal muscle myosin heavy chain isoforms: example of application to muscle denervation study. FEBS Lett.; 353: 13-5.

Kurabayashi M, Komuro I, Tsuchimochi H, Takaku F, Yazaki Y. (1988) Molecular cloning and characterization of human atrial and ventricular myosin alkali light chain cDNA clones. J Biol Chem.; 263: 13930-6.

Laemmli UK. (1970) Cleavage of structural proteins during the assembly of the head of bacteriophage T4. Nature.; 227: 680-5.

Lees-Miller JP, Helfman DM. (1991) The molecular basis for tropomyosin isoform diversity. BioEssays.; 13: 429-37.

Lompre AM, Nadal-Ginard B, Mahdavi V. (1984) Expression of the cardiac ventricular alpha- and beta-myosin heavy chain genes is developmentally and hormonally regulated. J Biol Chem.; 259: 6437-46.

Lowey S, Waller GS, Trybus KM. (1993) Skeletal muscle myosin light chains are essential for physiological speeds of shortening. $\mathrm{Na}$ ture; 365: 454-6.

Morano I. (1999) Tuning the human heart molecular motors by myosin light chains. $\mathrm{J} \mathrm{Mol}$ Med.; 77: 544-5.

Morano I, Haase H. (1997) Different actin affinities of human cardiac essential myosin light chain isoforms. FEBS Lett.; 408: 71-4.

Morano I, Bletz C, Wojciechowski R, Ruegg JC. (1991) Modulation of crossbridge kinetics by myosin isoenzymes in skinned human heart fibers. Circul Res.; 68: 614-8.

Morano I, Ritter O, Bonz A, Timek T, Vahl C, Michel G. (1995) Myosin light chain-actin interaction regulates cardiac contractility. Cirulc Res.; 76: 720-5.

Nieznańska H, Nieznański K, Efimova N, Kąkol I, Stępkowski D. (1998) Dual effect of actin on the accessibility of myosin essential light chain A1 to papain cleavage. Biochim Biophys Acta.; 1383: 71-81.

Periasamy M, Strehler EE, Garfinkel LI, Gubits RM, Ruiz-Opazo N, Nadal-Ginard B. (1984) Fast skeletal muscle myosin light chains 1 and 3 are produced from a single gene by a combined process of differential RNA transcription and splicing. J Biol Chem.; 259: 13595-604.

Podlubnaya Z, Malyshev SL, Nieznański K, Stępkowski D. (2000) Order-disorder structural transitions in synthetic filaments of fast and slow skeletal muscle myosins under relaxing and activating conditions. Acta Biochim Polon.; 47: 1007-17.

Price KM, Littler WA, Cummins P. (1980) Human atrial and ventricular myosin light-chains subunits in the adult and during development. Biochem J.; 191: 571-80.

Prince HP, Trayer HR, Henry GD, Trayer IP, Dalgarno DC, Levine BA, Cary PD, Turner C. (1981) Proton nuclear-magnetic-resonance spectroscopy of myosin subfragment 1 isoenzymes. Eur J Biochem.; 121: 213-19.

Rarick HM, Opgenorth TJ, von Geldern TW, Wu-Wong JR, Solaro RJ. (1996) An essential myosin light chain peptide induces supramaximal stimulation of cardiac myofibrillar ATPase activity. J Biol Chem.; 271: $27039-43$.

Schaub MC, Hefti MA, Zuellig RA, Morano I. (1998) Modulation of contractility in human cardiac hypertrophy by myosin essential light chain isoforms. Cardiovasc Res.; 37: 381-404.

Smillie LB. (1982) Preparation and identification of $\alpha$ - and $\beta$-tropomyosin. Methods Enzymol.; 85: 234-41.

Stępkowski D, Szczęsna D, Wrotek M, Kąkol I. (1985) Factors influencing interaction of phosphorylated and dephosphorylated myosin with actin. Biochim Biophys Acta.; 831: 321-9.

Strzelecka-Gołaszewska H, Jakubiak M, Drabikowski W. (1975) Changes in the state of actin during superprecipitation of actomyosin. Eur J Biochem.; 55: 221-30. 
Sutoh K. (1982) Identification of myosin-binding sites on the actin sequence. Biochemistry.; 21: $3654-61$.

Sweeney HL. (1995) Function of the N terminus of the myosin essential light chain of vertebrate striated muscle. Biophys J.; 68: $112 \mathrm{~s}-9 \mathrm{~s}$.

Sweeney HL, Kushmerick M, Mabuchi K, Sreter FA, Gergely J. (1988) Myosin alkali light chain and heavy chain variations correlate with altered shortening velocity of isolated skeletal muscle fibers. J Biol Chem.; 263: 9034-99.

Swynghedauw B. (1986) Developmental and functional adaptation of contractile proteins in cardiac and skeletal muscles. Physiol Rev.; 66: $710-74$.

Tartakowski AD. (1978) Methods of isolation and characterisation of skeletal striated muscle myosin and its subunits. In Biophysical and biochemical methods of investigation of muscle proteins. Pinaev GP. ed, pp 55-76. Nauka, Leningrad.

Timson DJ, Trayer HR, Smith KJ, Trayer IP. (1999) Size and charge requirements for kinetic modulation and actin binding by alkali 1-type myosin essential light chains. $\mathrm{J}$ Biol Chem.; 274: 18271-7. 